\title{
Maturidade da Conceituação de Relações Públicas
}

\author{
Sylla M. Chaves
}

\author{
INTRODUÇÃo
}

$\mathrm{T}$

ENDO abordado êste assunto em artigo anterior, (1) sugerindo que dêle trate a primeira unidade de um programa básico de relações públicas, parece-me indispensável distender-me um pouco mais, para explicar mais claramente as minhas idéias que, embora coincidam com as dos grandes mestres de relações públicas e opinião pública na América de hoje, não são ainda aceitas pela totalidade dos técnicos de relações públicas entre nós.

Variando a conceituação de relações públicas exatamente no que ela tem de mais fundamental, os seus objetivos e os seus campos de atividade, torna-se possivel desvirtuá-las de tal modo, que deixam de ser uma função altamente necessária para a administração pública ou a emprêsa moderna, no desempenho da sua missão social, e passam a ser, pelo contrário, uma atividade na qual os dinheiros públicos (no que tange à administração pública) ou o aumento do preço de venda de um produto (no sua missão social, e passam a ser, pelo contrário, uma atividade que, se fizéssemos parte do legislativo, teriamos a obrigação de procurar coibir.

E é por ter esta discussão teórica enormes conseqüências na prática que considero não ser demais voltar ao assunto, examinando-o em profundidade neste número da Revista. E ainda com maior razão, pois as idéias de que discordo estão sendo divulgadas nos dias que correm. Foram expressas junto com as minhas no Ciclo de Palestras recentemente patrocinado pela A.B.R.P.; (2) e também foram por mim colocadas nos Textos Selecionados de Administração Pública, (3) ainda no prelo, com a finalidade de despertarem o espírito crítico do leitor.

Indicarei, pois, mais uma vez e com maior detalhe, os objetivos, o objeto, os campos de atividades e os instrumentos desta nova função administrativa, para depois podermos comparar algumas das definições que nos oferece a já abundante literatura existente sôbre o assunto. 


\section{OBJETIVOS}

Como já foi dito, são os objetivos a parte mais importante e mais controvertida da conceituação de relações públicas. Sua evolução coincidiu com o amadurecimento por que passou a profissão no país em cujas emprêsas privadas se originou e se foi modificando, acompanhando as modificações por que passaram essas emprêsas em suas relações com a sociedade.

Êsse processo histórico tem várias etapas. O primeiro marco que força a evolução é o dos ataques aos capitães de indústria por parte, no além-mar, dos porta-vozes das doutrinas socialistas que começavam a germinar, e, em plena América, pelos chamados "muck-rakers" que, com sua pena ferina, abalavam o prestígio dos potentados econômicos.

Entre êsses "revolvedores de estêrco" estavam os famosos Upten Sinclair que, em sua novela $A$ Selva, expôs as irregularidades da indústria de carne enlatada, e Ida Tarbell, cuja História da Standard Oil produziu na opinião pública violentas reações contra essa emprêsa.

Surgiu, então, Ivy LEE, para alguns o "Pai das Relações Públicas", para Sinclair e "poison-ivy", para o professor Smith, da Universidade de Chicago, um "plutogogo", e para outros o "irmãozinho dos ricos". IVY LEE conseguiu reabilitar Rockefeller perante a opinião pública, dai lhe advindo grande popularidade e dinheiro. Seu aparecimento na cena de relações públicas ocorreu em 1906, quando distribuiu aos jornais de Nova Iorque sua famosa declaração de principios:

"Êste não é um departamento de imprensa secreto. Todo o nosso trabalho é feito às claras. Pretendemos divulgar notícias, e não distribuir anúncios. Se acharem que o nosso assunto ficaria melhor como matéria paga, não o publiquem. Nossa informação é exata. Maiores detalhes sôbre qualquer questão serão dados prontamente, e qualquer redator interessado será auxiliado, com o máximo prazer, na verificação direta de qualquer declaração de fato... Em resumo, nosso plano, com absoluta franqueza, para o bem das emprêsas e das instituições públicas, é divulgar à imprensa e ao público dos Estados IInidos, pronta e exatamente, informações relativas a assuntos com valor e interêsse para o público". (4)

A evolução de relações públicas ainda não atingira a maturidade, mas já havia sinais de um grande progresso relativamente do período anterior ao passar do século, caracterizado pelo descaso 
de Vanderbilt e pela mistificação de Barnum. Desde êsse momento, a informação em relações públicas passout a ser considerada mais importante do que a persuasão, conforme veremos no capítulo destinado a êsses campos de atividades. A preocupação com as portas abertas, bem como com a exatidão e o interêsse público das notícias, passou a ser uma coordenada indispensável para a definição dos objetivos de relaçóes públicas; podemos resumi-los nessa fase, como sendo a compreensão e aceitação de nossa instituição por parte da opinião pública, angariadas através dos recursos lícitos da persuasão e da informação.

Mas a evolução continuou. Os cientistas sociais trouxeram a sua contribuição através das obras inovadoras de WALTER Lipmann (Opinião Pública, 1922) e Bernays (Cristalização da Opinião Pública, 1923), fazendo com que a opinião pública deixasse de ser tratada como simples "massa moldável" ao belprazer dos técnicos dos veículos de massas, para ser considerada também em seu dinamismo, em suas razões profundas, em seus interêsses, e para que todo o problema ético fôsse reformulado. "O público precisa ser compreendido" - é o lema seguido desde então pelos homens de relações públicas. E BERnays estabelece u seu famoso principio da bilateralidade, ao definir as atividades de um consultor de relações públicas com um especialista que dge tanto sôbre as massas quanto sôbre a própria instituição que $u$ contratou. E essa ação êle soube levar da teoria para a prática nos seus já quarenta anos de atividades como o mais famoso consultor de relações públicas dos Estados Unidos.

Eis a função do consultor de relações públicas segundo BERNAYS:

"1. Definir os objetivos sociais de seu cliente, ou ajudar a defini-los.

2. Descobrir os desajustamentos existentes entre êsses objetivos e os vários elementos de nossa sociedade, dos quais nosso cliente depende. Êsses desajustamentos podem ser distorções na mente do público devidas a informação errada, ignorância ou apatia, ou podem ser distorções devidas a ação errada por parte do cliente.

3. Procurar ajustar as diretrizes e ações de seu cliente à sociedade, para solucionar os desajustamentos.

4. Aconselhar seu cliente sôbre as maneiras como suas novas politicas e ações, ou suas velhas politicas e ações, se tiver sido considerado aconselhável conserválas, podem ser tornadas compreensiveis ao público". (5). 
Intencionalmente citei aqui não o BERNAYs de 1923, mas o BERNAYS do após-guerra, com a fôrça redobrada que suas idéias adquiriram, em virtude da cabal demonstração de sua exatidão proporcionada pela Grande Depressão. A responsabilidade social da emprêsa, depois de 1930, tornou-se fato indiscutivel, pois podem seus atos levar metade do mundo ao descalabro, conforme se verificou. A única maneira de justificar o sistema da livreemprêsa é demonstrar que, no que lhes concerne, o interêsse público e o interêsse privado podem e devem coincidir.

O principio da bilateralidade é, por conseguinte, para BERNAYS e para mim, não apenas a bilateralidade dos meios - informações em ambos os sentidos -, mas também, e principalmente, a bilateralidade dos fins - e interêsse mútuo a ser buscado pelo especialista, como condição indispensável para que suas atividades possam ser consideradas como de relações públicas.

$\mathrm{E}^{\prime}$ por isso que CHILDS, definindo-as a partir dos seus objetivos, diz que "relações públicas é o conjunto de atividades destinadas a pôr de acôrdo com o interêsse público todos os aspectos do comportamento individual ou institucional que tenham significado social". (6) E também o Instituto Britânico, em definição que serviu de base para a adotada pela A.B.R.P., (7) indica ser relações públicas "... o esfôrço ... para estabelecer e manter a compreensão mútua entre uma organização e os seus públicos".

Os objetivos de RP na época atual de maturidade da profissão são, por conseguinte, a compreensão mútua, a interêsse mútuo, a coincidência entre $o$ interêsse público e o interêsse privado.

Se quiséssemos dar aqui uma ordem de prioridade a êsses objetivos, nossas considerações filosóficas seriam bastante complexas, porém desnecessárias, pois, quer o interêsse público seja para nós um fim em si, quer seja êle o caminho para alcançar n nosso próprio interêsse, o que importa é têrmos sempre o interêsse público em nossas cogitações.

Paul Garret, diretor de relações públicas da General Motors, considera relações públicas "uma atitude fundamental da mente, uma filosofia de administração que, deliberadamente $e$ com esclarecido egoísmo, dá preferência aos interêsses do público, em qualquer decisão que envolva a atividade da emprêsa". (8)

Será relações públicas um fruto de altruísmo ou de egoísmo esclarecido? Será o interêsse público um fim em si ou um meio para chegar ao interêsse privado? Pensarão homens como Rockefeller, ao criar as suas fundações, no interêsse público por elas servido, ou na reputação que vão angariar? E na administração pública, os políticos que a dirigem estarão pensando principalmente na satisfação do interêsse público pelo correto desempenho 
de sua missão, ou estarão primeiramente pensando nas vantagens que daí advirão para a sua carreira politica? E' difícil, ou mesmo impossivel, sabê-lo.

Podemos acreditar que, praticando relações públicas como aqui se preceitua, os homens estão apenas aplicando a lei divina, tão bem interpretada nesta passagens da encíclica Rerum Novarum: "Quem quer que tenha recebido da divina Bondade maior abundância de bens, quer de bens externos e do corpo, quer de bens da alma, recebeu-os para fazer servir ao seu próprio aperfeiçoamento e ao mesmo tempo, como ministro da Providência, ao alivio dos outros". Está também contida na passagem do Quadragésimo Ano onde o Sumo Pontífice indica ser fundamentalmente necessária "a reinserção do mundo econômico na ordem moral e a harmonização dos interêsses, quer dos indivín duos, quer dos grupos, com o bem comum".

O utilitarismo de BentHAN, considerando, como HobBes e HeLvÉCio, que o principio único de nossas ações é o interêsse pessoal, também conduz ao interêsse geral. Para êle, todos os homens são essencial e necessàriamente egoístas. A moral é a "regularização do egoísmo", e o critério do bem é o cálculo do maior prazer, cuja avaliação êle faz por uma "aritmética moral". BENTHAN nega, porém, a oposição entre o interêsse particular e o interêsse geral, chegando ao acôrdo entre o interêsse e a virtude e entre o interêsse e a justiça, por considerar que, "uma vez pesados os diversos prazeres, escolhe-se aquêle que é superior em quantidade". E como "o próximo nos devolve, por assim dizer, o bem que lhe causamos, da mesma forma como um espelho nos devolve a luz", chega BentHAn, por êsse raciocínio, a considerações filantrópicas. (9) Sua filosofia serve, pois, de base à definição de PauL Garret.

Quer sejamos "egoístas esclarecidos", quer sejamos altruístas, nosso objetivo último, como homens de relações públicas. é a identificação do interêsse privado de nossa instituição com o interêsse público, pois só quando coincide inteiramente com o interêsse público é que o interêsse privado pode ser atingido pela instituição com a completa aquiescência e colaboração da sociedade.

\section{OBJETO}

"Os problemas de relações públicas são, em sua essência, problemas de opinião pública". (10) Consistindo relações públicas na "continua interação de guiar a opinião pública e, ao mesmo tempo, ser por ela guiado", (11) pode a linguagem figurada de CHILds afirmar que a opinião pública é para o técnico de relações 
públicas, simultâneamente, o seu "termômetro", a sua "massa moldável" e o seu "guia". (12)

E' pelo bom ou mau conceito em que uma instituição é tida pela opinião pública que sabemos se as suas relações públicas são boas ou más. A pesquisa de opinião serve, pois, para "tomar a temperatura" das relações públicas de uma determinada instituição.

Faz parte da tese de CHILDs, com sua concepção democrática de relações públicas, a afirmação de que, pelo menos no que se refere aos Estados Unidos, o interêsse público é o que a opinião das massas indica, opinião das massas significando as opiniões coletivas da totalidade do povo. "A teoria de que a revelação divina através de canais humanos específicos deu a um homem ou a um grupo de homens uma visão prévia do interêsse público está perdendo pouco a pouco a sua fôrça de convencimento. Descobriram as massa que há menos perigo em aceitar que a divindade revela o interêsse público através da mente das massaś do que em acreditar que ela revela êsse interêsse através de individuos ou grupos especialmente inspirados". (10) E' a reafirmação do "vox populi - vox Dei" dos romanos.

" $\mathrm{E}$ ' claro que a competência das massas para indicar o interêsse público depende das oportunidades que tem de adquirir informação, de ouvir diferentes pontos-de-vista, de discutir e expressar suas opiniões livremente, e de usar sua faculdade de raciocínio". (10)

Por outro lado, reconhecendo a inércia das massas e a atividade de grupos minoritários, afirma CHILDs que "a única maneira para introduzir uma nova politica é conseguir para ela a aceitação da maioria. "Todos nós temos idéias próprias sôbre a maneira de salvar o mundo, e podemos tentar persuadir o público a aceitá-las. Entretanto, enquanto o apoio público não fôr conseguido, não há justificativạ para aplicá-las". (6)

Dessa forma, podemos compreender claramente a "continua interação de guiar a opinião pública e, ao mesmo tempo, ser por ela guiado", o técnico de relações públicas não sòmente tendo o dever de conformar-se à opinião pública, mas também tendo a responsabilidade e oportunidade de moldá-la e guiá-là. (11)

Por tudo o que foi dito, sente-se que o objeto, a "matériaprima" com que trabalham as relações públicas, é a mente humana, em seu aspecto coletivo, que encontra sua expressão na opinião pública. Não é possivel pẹnsar em trabalho de relações públicas que se despreocupe, por um, momento sequer, de con' siderações relativas à opinião pública. Por outro lado, a recíproca é também verdadeira, pois, como faz notar CHILDs "o estudioso de opinião pública logo descobre que os que mais realisticamente 
se preocupam com êste campo de estudo são aquêles que estão procurando resolver problemas de relações públicas". (10)

E o que é a opinião pública? Segundo CHILDS, "é qualquer coleção de opiniões individuais, independentemente do grau de acôrdo ou uniformidade". (10) Mais esclarecedora, entretanto, parece-nos a posição de William Albig: "A nosso ver, opinião é qualquer manifestação sôbre assunto controvertido. A opinião pública resulta da interação de indivíduos uns com os outros, em qualquer tipo de grupo ... Pode haver ou deixar de haver uma maioria que expresse uma opinião geral. O processo da opinião é a interação que ocorre dentro de um grupo com relação a um assunto controvertido. A opinião de grupos é o produto dessa interação ... Essa opinião de grupo não é estática, mas evolui, à proporção que novos elementos são introduzidos na discussão. A opinião pode decorrer de uma análise e procedimento raciocinados e lógicos. Em grandes grupos ela provém, mais freqüentemente, de sentimento, emoção, impressões casuais e vários elementos ilógicos".

Essa realidade complexa que é a opinião pública é, pois, o objeto de qualquer trabalho de relações públicas, havendo três maneiras fundamentais de utilizá-la: o homem de relações públicas transmite-lhe informações, modela-a ou se integra com ela, na contínua interação indicada por CARLSON. E são essas três maneiras fundamentais de o técnico relacionar-se com a opinião pública que BERnays considerou os três campos de atividade de relações públicas: informação, persuasão e integração.

\section{CAMPOS DE ATIVIDADE}

\section{Considerações gerais}

Para atingir os seus objetivos, e manipulando o setı objeto - a opinião pública — o técnico de relações públicas informa os públicos, dêles também trazendo informações para a instituição, persuade-o a modificar suas opiniões e atitudes e, "na contínua interação de guiar e ser guiado", busca a integração da instituição com os seus públicos.

Êsses três campos de atividade pressupõem uma fase prévia de trabalho, uma fase de pesquisa, documentação e planejamento, que poderiamos considerar, no seu conjunto, como um quarto campo de atividade. A pesquisa, tanto sôbre a instituição quanto sôbre os públicos e os veículos de comunicação, é indispensável para que a informação, a persuasão e a integração possam ser realizadas com eficiência.

Podemos representar com o quadro abaixo (fig. 1) a divisão de relações públicas em seus campos de atividade. 
(FIG. I)

Campos de atividade de RP:

DEMOCRACIA

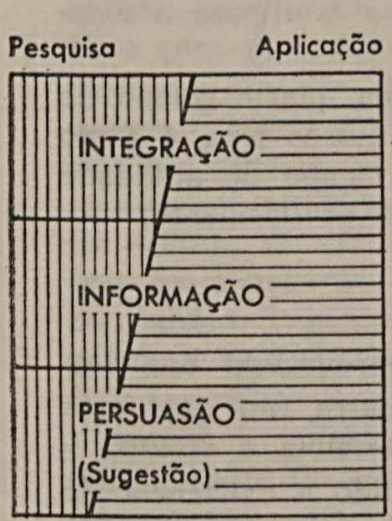

Fora de RP

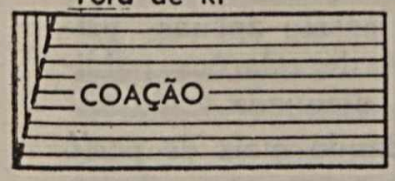

USO DE FORÇA

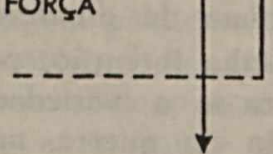

- AUTOCRACIA.

Os campos de atividade de relações públicas foram colocados nesse quadro não na ordem em que BERnAYs os enunciou, mas na de seu caráter mais ou menos democrático. Vindo da autocracia para a democracia, encontramos, em primeiro lugar, o recurso da coação, uso da fôrça para conseguir uma mudança de atitudes (evidentemente consideradas em seu aspecto objetivo, e não subjetivo). A coação é uma atividade alheia a relações públicas. Embora esta afirmação pareça óbvia, será necessário voltar a ela, em virtude das contradições que parece conter, visto poder-se falar em relações públicas de entidades nitidamente coatoras, como é o caso das classes armadas, da polícia, dos paises beligerantes, etc.

Já entrando no terreno das relações públicas, os campos de atividade de BERNAYs, no sentido da autocracia para a demo- 
cracia, colocam-se nesta ordem: persuasão, informação e integração. Êste último é, evidentemente, o mais democrático dos três, e, por isso mesmo, o mais raro na prática de hoje. E' êle o campo que corporifica a bilateralidade das relações públicas, e que as distingue de que seria mera publicidade institucional. $\mathrm{E}^{\prime}$ o que caracteriza a fase atual de evolução das relações públicas, designada por BeRnays como "era da integração". Apesar da negligência atual, é ela condição sine qua non para a existência de relações públicas.

A pesquisa, que pode ser considerada um quarto campo de atividade, que precede cronològicamente os outros três, é tanto mais necessária quanto mais democrático o campo de atividade a que se destina, conforme foi representado gràficamente.

\section{COAÇÃo}

Famoso manual de direito público internacional tem um capítulo sôbre o direito internacional na guerra, no qual está dito apenas que, quando começa a guerra, termina o direito.

Pode-se ser igualmente categórico, negando a existência de relações públicas tôda vez que um dos interlocutores é cerceado pela coação. Considerando ainda a existência da "violência psíquica", forma de coação de que fala Tchakhotine, (13) pode-se negar in toto a existência de relações públicas entre os participantes em uma guerra, mesmo "fria", mesmo apenas "psicológica". Negar-se-ia, também, a existência de relações públicas em qualquer clima de ditadura, mesmo atenuada.

Não é essa minha intenção, pois, abordando mais de perto o problema, verifica-se a variedade de situações que admite. Se dois paises estão em guerra, nada impede que ambos pratiquem relações públicas em tôda a sua plenitude com relação a um terceiro país, alheio às operações bélicas, quer realizadas por tanques, quer por emissoras radiofônicas ou panfletos clandestinos.

Da mesma forma, se a autoridade máxima de um país é ditatorial, nada impede que entidades públicas ou privadas dêsse país pratiquem relações públicas, em tôda a sua plenitude, dentro dos limites de sua competência, como sói acontecer, por exemplo, com emprêsas privadas democráticas subordinadas à ditadura franquista.

A coação não é nunca campo de atividades de relações públicas, mas relações públicas podem sempre ser aplicadas apesar da coação, ou mesmo como complemento a ela. A polícia que prende o ladrão e o mantém prêso, pode preocupar-se com os problemas dêste, e com muitos dos seus anseios, embora não 
lhe seja possivel concordar com o seu "anseio de liberdade". Excluindo a própria coação e tudo quanto com ela se relaciona diretamente, tudo o mais permite a aplicação de relações públicas. E êsse campo é vastíssimo, como já demonstraram as penitenciárias que se dispuseram a aplicar relações públicas.

Quando os detentores do poder aceitam uniformemente uma filosofia politica ou religiosa, há sempre um setor de suas atividades que êles não permitem seja discutido pela opinião pública. $\mathrm{E}^{\prime}$ o caso da coação exercida pelos governos marxistas, no que tange à filosofia básica do seu regime; da mesma forma, a Igreja Católica não aceita que um plebiscito decida se deve ou não instituir no Brasil a lei de divórcio, e os governos islâmicos não aceitam a pressão da opinião pública internacional no sentido de ser proibida a poligamia. E' êsse o campo em que os detentores do poder se consideram também "detentores da verdade", justificando dêsse modo a sua coação. Repito as palavras de CHILDs, há pouco citadas: "Todos nós temos idéias próprias sôbre a maneira de salvar o mundo, e podemos tentar persuadir o público a aceitá-las. Entretanto, enquanto o apoio público não fôr conseguido..." E conclui de outra forma: ... enquanto o apoio público não fôr conseguido, sua imposição pela fôrça está totalmente fora dos limites de relações públicas.

Talvez possa parecer que considero que o técnico de R.P. não deva ter conviç̧ões. Não se trata disso. Entretanto, cada vez que êle queira impor suas conviç̧ões pela fôrça, êle estará não só fugindo à solução democrática do caso, mas também recusando o caminho das relações públicas, têrmos que freqüentemente se confundem. Por outro lado, sempre que suas convicções não interferem no livre diálogo com a opinião pública, em busca do interêsse mútuo e utilizando essa opinião pública para identificar o interêsse público, estará havendo prática de relações públicas.

\section{PERSUASÃO}

Se o caminho da fôrça é vedado aos técnicos de relações públicas, êsses técnicos, que têm a oportunidade e a obrigação de guiar a opinião pública, na continua interação que com ela mantêm, devem recorrer às técnicas do convencimento, no campo de atividade que Bernays denominou persuasão, mas que além dela - apêlo à razão - inclui também a sugestão - apêlo ao sentimento. Como vimos na citação de William Albig, a opinião pública "provém, mais freqüentemente, de sentimento, emoção, impressões casuais e vários elementos ilógicos". E é principalmente nesse terreno ilógico, emocional, que o convenci- 
mento de hoje costuma ingressar com maior frequiência, como bem descrevem Vance Packard (14) e Tchakhotine. (13)

Afirma Rex Harlow que a tarefa que melhor representa a função do homem de relações públicas é a de "persuadir as pessoas a tornar-se e continuar amigos, fregueses e clientes de seus empregadores. Sua eficiência mede-se, em última análise, pela sua habilidade em conquistar as mentes e os corações das pessoas para a causa ou atividade a que êle serve. Se êle não é capaz de persuadir, êle não é realmente um homem de relações públicas". (15)

Já tive a oportunidade de, apoiado em inúmeras citações, demonstrar o êrro em que incorre HARLOW ao dar essa importância exagerada ao uso da persuasão em relações públicas. (1) $\mathrm{O}$ que aqui foi dito relativamente aos objetivos e ao objeto de relações públicas serve também para indicar que essa não é a tarefa principal, pois mais importantes que ela são aquelas que BERNAYs enumerou ao definir a função do consultor de relações públicas.

Se volto ao assunto é porque essa citação, embora não indique corretamente o que se deve fazer, indica, infelizmente, o que geralmente se faz.

Ao dizer não apenas "tornar-se amigos", mas também "tornar-se fregueses", Rex HarLow claramente se afasta da quase totalidade dos teóricos, mas, infelizmente, aproxima-se da prática de alguns "técnicos" no assunto... Estamos cansados de saber que angariar fregueses é finalidade da publicidade comercial, relacionada com o setor de vendas, enquanto que conseguir amigos é finalidade da publicidade institucional, só esta última tendo relação direta com relações públicas.

Isto está bem claro nas palavras do Dr. Arnaldo Sehwerert Ferrer, personalidade destacada da Federação Interamericana de Associações de Relações Públicas, com obras divulgadas em tôda a América Espanhola. Diz êle: ' $E$ ' claro que as relações públicas podem trazer como conseqüência um aumento no volume de vendas de uma emprêsa comercial qualquer, mas êsse não é o fim fundamental que se busca..." Êsse fim é, em última análise, "solidarizar a emprêsa com o público e o público com a emprêsa". (16) (o grifo é nosso).

Outra idéia implícita na afirmação de Harlow é a de que relações públicas servem para conquistar não só as mentes, mas também os corações das pessoas. Percebe-se que êle se está referindo não só à persuasão, mas também à sugestão, também aos "hidden persuasers" (persuasores ocultos) da VANCE PACKARD.

Caberia, mais uma vez, tratar de assunto da licitude da persuasão e da sugestão em relações públicas, como foi feito no 
artigo anterior. Considero ambas lícitas, desde que não se afastem nunca do interêsse público, conforme indicou CHILDs. O empregador (que, digamos a titulo de comparação, no caso de GoEbBELS, se chamava Hitler) foi o único têrmo de referência utilizado por Harlow. Bernays é que coloca os pingos nos ii, considerando indispensável que o consultor de relações públicas, antes de mais nada, procure "definir os objetivos sociais de seu cliente" e "ajustar as diretrizes e ações de seu cliente à sociedade". Esta sim, é que é a "tarefa que melhor representa a função de homem de relações públicas". O mais é simples decorrência disso.

Segundo BAus, "a administração atual contrata conselheiros de relações públicas, permanentes ou não, para orientá-la quanto à opinião pública e auxiliá-la a manter um contrôle sadio de sua politica, dirigindo-a, aplicando-a corretamente às condições mutáveis". (17)

Para que o homem de relações públicas possa lançar-se à persuasão e à sugestão, tem êle, por conseguinte, um trabalho prévio de determinação da direção a seguir. O convencimento da opinião pública não pode ser feito em qualquer sentido. O caráter anti-social da propaganda de Goebbels fêz com que êle se colocasse contra o interêsse público e, por definição, fora de relações públicas, pelo menos nesse momento.

Comparemos aqui, a título de esclarecimento, a persuasão que usam duas atividades afins a relações públicas: a propaganda e a educação de massas. A semelhança na forma é muito grande, pois sabemos que a entidade máxima da educação no mundo, a UNESCO, se queixa da utilização indevida dos manuais escolares, em pràticamente todo o mundo, por se inserirem nêles, principalmente nos manuais de história, meias verdades que falseiam os fatos, em benefício de uma propaganda nacionalista ditada por um falso espírito de civismo. Os mesmos veículos que transmitem a propaganda são os que transmitem a educação de massas, ambas contendo um certo elemento persuasório. Qual é, pois, a diferença entre elas?

Há aqui um problema de terminologia. O que é a propaganda? Como defini-la? Não tenho nenhum interêsse em salvar êsse têrmo da lama aonde foi jogado por Goebbels e por muitos continuadores seus, tanto na politica quanto no comércio; utilizo-o, portanto, em falta de outro, para designar a utilização da persuasão (tão freqüentemente feita com êsse rótulo) visando ao interêsse individual e sem nenhuma consideração quanto ao interêsse público. Segundo Benedicto Silva, em seu estudo clássico sôbre o assunto, (18) o propagandista é úm "forjador de mitos", que apresenta uma "realidade profissionalmente retocada" que, 
em vez de favorecer ao público, solicita o seu favor. Na educação, a persuasão é também elemento essencial, mas desta vez o favorecido é o público. Como já tivemos a oportunidade de ver, relações públicas buscam o interêsse mútuo, coincidindo, por conseguinte, muito mais freqüentemente com a educação de que com a propaganda. A propaganda traz consigo a idéia de concorrência, ao passo que a educação e as relações públicas trazem consigo a idéia de cooperação.

Tive a oportunidade de citar Sauvy que, considerando que a propaganda deforma a verdade, ao selecionar os fatos, procurando forjar autômatos e não pensadores, afirma estar ela "no pólo oposto à democracia, tal como foi a democracia concebida pelos idealistas". (19)

BERNAYS, entretanto, usa o têrmo propaganda com outra acepção. Diz êle: "Novas atividades exigem uma nova nomenclatura. O propagandista que se especializa na interpretação de emprêsas e idéias ao público, e na interpretação do público aos dirigentes de novas emprêsas e lançadores de novas idéias passou a chamar-se consultor de relações públicas". (20) Para êle, propaganda é um têrmo geral, que abrange tudo o que até agora foi aqui tratado. Os homens de relações públicas são, por conseguinte, um nôvo tipo de propagandistas, enquanto que o que foi descrito por mim, por Sauvy e por Benedicto Silva é o propagandista de velho tipo". Tudo é uma questão de terminologia. Opto, pois, pela acepção restritiva do têrmo propaganda.

O conteúdo persuasório e sugestivo de relações públicas, a meu ver, está no terreno da educação cívica, da educação agricola, da educação sanitária e, mais raramente, no da publicidade institucional, nos momentos em que ela deixa de ser uma simples transmissão de informações. Não se pode aceitar como relações públicas nem a propaganda comercial, nem a propaganda política, que cabem em departamentos de vendas e em partidos políticos, mas nunca em departamentos de relações públicas.

Não estou afirmando que o homem de relações públicas não se deve preocupar com a propaganda que outros realizam. Deve, e muito. Se suas atribuições, como indica CHILDs, consistem em "pôr de acôrdo com o interêsse público todos os aspectos do comportamento individual ou institucional que tenham significado social", não podemos negar que a propaganda realizada por uma instituição deve preocupar o técnico de relações públicas, pois é indiscutivel que a propaganda tem sempre um grande significado social, no bom ou no mau sentido.

A solução do problema, entretanto. é fácil. Quer se trate de uma entidade política, quer se trate de uma entidade comercial, em ambos os casos não é o departamento de relações públicas 
o órgão competente para executar as atividades de propaganda. Ele é, porém, competente para verificar se essa propaganda está ou não sendo executada de acôrdo com o interêsse público. Caso não esteja, cabe-lhe propor a sua modificação, com base no interêsse público. Se a instituição é pequena, devendo um mesmo órgão executar várias funções, o mesmo individuo pode encarregar-se de propaganda e relações públicas, mas esta é, evidentemente, uma situação excepcional.

\section{INFORMAÇÃO}

O segundo campo de atividade responde simultâneamente à necessidade que tem a instituição de ser conhecida e à sua obrigação de prestar informações. A responsabilidade social das emprêsas faz com que essa não seja apenas uma obrigação dos órgãos governamentais.

Ao receber das mãos do Diretor-Geral da UNESCO, em abril de 1960, o prêmio Kalinga, afirmou JEAN Rostand que "a obrigação de sofrer as conseqüências justifica plenamente o direito de ser informado". E continuou: "Todos os homens têm o direito de receber a verdade, e a verdade tem o direito de chegar a todos". (21)

Mas o que é a verdade? Qual poderia ser o princípio da veracidade que muitos querem introduzir em relações públicas?

A honestidade, sinceridade, lealdade ou veracidade para mim não constitui um princípio de relações públicas. E' mais do que isso. E' um pressuposto, tanto de relações públicas quanto de qualquer outra profissão aceita pela sociedade. Além disso, temos ai as variações decorrentes da definição de verdade: verdade total ou parcial? O que julgamos ser a verdade com mais ou com menos convicção? Isso faz com que a mentira para um seja a verdade para outro, desde que colocados em pólos políticos ou religiosos opostos. O caráter íntegro é talvez mais importante em relações públicas de que em outras profissões, em virtude de sua grande relevância social. Mas o que é o caráter integro? A integridade refere-se só aos fins, ou também aos meios? O meio - verdade ou mentira - será justificado pelos fins? Infelizmente. parece ser esta hoje em dia a opinião não só de marxistas, que a tiram de sua doutrina, mas também de muitos antimarxistas.

Inicialmente, busquemos saber o que é a verdade, acompanhando PASCAL em um de seus pensamentos. "A vontade diz êle - é um dos principais elementos da crença: não que ela constitua a crença, mas porque as coisas são verdadeiras ou falsas conforme o lado por onde são vistas. A vontade, que prefere um lado a outro, afasta o espírito das considerações sôbre 
as qualidades daquele lado que ela não quer ver; e assim o espirito, marchando juntamente com a vontade, detém-se para contemplar o lado que ela prefere; e assim, êle julga segundo o que êle vê". (22). E podemos acrescentar, à guisa de conclusão, uma frase de ANDRÉ GIDE, extraída de suas "Nourritures Terrestres": "E tu parecerás, Natanael, alguém que, para guiarse, seguiria uma luz que êle próprio estaria segurando com sua mão". (23)

A imperfeição humana faz com que conheçamos da verdade apenas a imagem imperfeita que nossos sentidos trazem dela. A primeira preocupação deve ser conhecer a verdade, verificá-la, comprová-la, com os parcos recursos humanos disponíveis, antes de procurar transmiti-la. E depois? Deve-se transmiti-la tôda, ou apenas parte dela?

Como a coação, a mentira, afirmação de fatos totalmente inverídicos, não pode ser aceita. Havendo quem justifique a guerra, há também quem justifique a mentira, precioso ingrediente da "guerra psicológica". Não se pode, porém, considerar que nesses casos se esteja praticando relações públicas.

Mas a mentira não é a única "inverdade" que existe. A verdade parcial é invocada em nome do "segrêdo profissional", da "segurança do Estado", do "amor familiar", e mesmo do próprio interêsse público, para o qual notícias alarmistas, divulgação de crimes e outros assuntos semelhantes podem ser prejudiciais.

Segundo PimlotT, entretanto, "a forma mais comum de deturpação da verdade é a supressão da informação desfavoráveI à instituição. Poucos diriam que isso nunca é permissivel. E' claro que devemos considerar o caso com certa largueza de visão; ninguém contratará um consultor de relações públicas para denegrir a sua reputação, da mesma forma como ninguém contratará «m advogado para assegurar a sua condenação. Pode haver circunstâncias em que a boa politica é antecipar-se às críticas e divulgar um êrro, mas não se pode esperar que uma organização venha lavar tôda a sua roupa suja em público". E Pimlotr, analisando o que ocorre nos Estados Unidos, cita vários exemplos do que afirma, inclusive o do próprio IVY LEE, cuja firma foi acusada por uma comissão do Congresso de ter sido contratada, em 1934, pelo German Dye Trust para "ajudar a corrigir as reações americanas quanto aos acontecimentos na Alemanha". (24) Evidentemente, num caso como êsse só poderiam ter sido levados ao público fatos selecionados...

Não chego ao extremo de considerar a realidade descrita por Pimlot como o que deve ser feito. Pelo contrário. O direito s̉e cada um de conhecer a verdade deve ser respeitado, a não ser que haja alguma razão muito forte para não proceder assim. 
E' interessanie ver como o amadurecimento produz a ponderação. Tal aconteceu com o símbolo de homem integro e amante da verdade que foi AlfREDo VARELA, o qual, "com leituras aprimoradas de tolerância a fim de bem exercer os seus misteres consulares, riscou de suas normas o seu veritas super omnia, substituindo-o por um princípio de GANGANELLI aquêle que mais tarde se tornou o grande papa Clemente XIV - de la verdad la mitad de la mitad". (25)

A informaçăo é básica para relações públicas. A verdade caracteriza-a. Entretanto, o bom técnico de relações públicas é aquêle que, além de saber falar, sabe também ouvir... e, algumas vêzes, calar.

\section{INTEGRAÇÃO}

Eis a parte mais democrática das relações públicas, o campo de atividade por meio do qual a instituição se integra na comunidade.

Como a informação, a integração é bilateral. A instituição se integra na comunidade $e$, ao mesmo tempo, faz com que os públicos também se integrem na instituição.

Em primeiro lugar, a integração começa em casa, com o público interno, para que depois a instituição, como um todo unido, possa integrar-se na sociedade.

E teremos dois aspectos a considerar na bilateralidade da integração:

1\%) a instituição vai em auxilio da comunidade, na medida de suas possibilidades correspondendo aos anseios desta, mesmo naquilo que não é sua específica obrigação;

2) a instituição pede o auxilio da comunidade para juntos, com a participação de todos, caminharem rumo aos objetivos comuns. E eis-nos chegados à harmonia final, à integração considerada como fim, depois de percorridas as etapas acima indicadas, Integração como meio, integração como campo de atividade.

\section{PESQUISA}

A pesquisa, com a documentação correspondente, pode ser considerada como um quarto campo de atividade, aquêle cuja finalidade consiste em fornecer e organizar os dados indispensáveis ao funcionamento dos outros campos de atividade.

Como a integração, também a pesquisa só recentemente foi "descoberta" pelos homens de relações públicas. E' necessário "que o público seja compreendido", afirmou Bernays em 1923, 
dando início à fase atual de evolução das relações públicas e abrindo caminho para que nelas penetrassem as ciências sociais com vários tipos de pesquisa que trazem consigo.

Nos últimos dez anos, as revistas de relações públicas têm tido abundantes artigos sôbre a necessidade de pesquisa em R.P. De artigos dêsse tipo resultou o recente livro de Rex Harlow que, apesar das imperfeições anteriormente citadas, traz uma qrande contribuição para a aproximação entre os técnicos de relações públicas e os cientistas sociais. Muito interessante é a sua descrição das pesquisas cujos resultados são aplicáveis em relações públicas. A atenção, o interêsse, a motivação e a liderança são algumas de suas preocupações.

A pesquisa de relações públicas refere-se a cada um dos três elementos existentes em qualquer situação de relações públicas: a instituição, os públicos e os instrumentos de comunicação entre êles. Começando pelo estudo de material existente em bibliotecas e arquivos, passa-se depois à pesquisa de campo, à análise dos recortes de jornais, dos inquéritos de opinião pública, etc. Tudo isso compilado e catalogado constitui a documentação de relações públicas, necessária para um planejamento consciencioso e para uma ação eficaz.

\section{INSTRUMENTOS}

São inûmeros os instrumentos utilizáveis nos vários campos de atividade de relações públicas. Cada vez mais numerosos, complexos e poderosos, principalmente os de informação e persuasão, exigem dos técnicos um conhecimento cada vez mais especializado.

Instrumentos de pesquisa típicos de relações públicas, além dos inquéritos de opinião pública e dos recortes de jornais, são também as caixas de críticas e sugestões, a análise da correspondência recebida, etc.

Instrumentos típicos de integração são, além dos instrumentos de pesquisa, necessários para que, conhecendo a opinião pública, a instituição se adapte a ela: reuniões de líderes de grupos, de amigos de bairros, e muitos outros.

Finalmente, os instrumentos de persuasão e informação, que são em essência os mesmos, usados de uma ou de outra forma, são aquela infinidade de instrumentos, cujo progresso se acelerou nos últimos anos, e que podem ser classificados da seguinte forma:

a) Veículos de divulgação ou de massas, que são, com as suas múltiplas variedades, os quatro que hoje em dia nos põem 
em contato com o grande público: em ordem cronológica, a imprensa, o cinema, o rádio e a televisão;

b) veículos de contato com públicos específicos e de âmbito mais restrito: impressos de vários tipos (relatórios, folhetos, cartas circulares, etc.), auxilios audiovisuais (filmes para uso restrito, filmes fixos, diapositivos, fotografias, cartazes, discos, fitas eletromagnéticas, etc.) e outros, que tanto podem ser enviados aos públicos a que se destinam quanto ser utilizados em conferências, exposições, visitas dirigidas, etc.;

c) contato pessoal: cartas, telefone e contato direto, os quais, considerados na sua pluralidade ou na sua importância ocasional e imprevisivel, são sempre essenciais em relações públicas.

\section{DEFINIÇÃO}

Como foi dito, já passou a época em que as relações públicas estavam, na expressão de CARLSON, "no estado fluido de definir-se a si mesmas". (11) Pode-se agora esperar uma resposta completa e definitiva à pergunta: o que é relações públicas?

Os objétivos nítidos, o objeto indiscutivel e os campos de atividade bastante claros desde o surgimento de BERNAYS, não deveriam permitir mais dúvidas.

Entretanto, elas subsistem, tanto na prática quanto na teoria, introduzidas principalmente por elementos formados na escola da prática.

$\mathrm{Da}$ mesma forma como temos as definições de CHILDs e GarRET, que consideram acima de tudo os objetivos e a atitude fundamental do espirito com que êsses objetivos são buscados, homens práticos recusam-se a reconhecer a existência de objetivos especificos em relações públicas. Para êles, relações públicas não é nada mais do que uma técnica, um método.

Afirma Henry Obermeyer que "as emprêsas privadas reduzirão muitas dessas concepções pretensiosas a um denominador comum, que é a comunicação hábil de idéias com o objetivo de produzir um resultado desejado". (26) E Simas Pereira sintetiza a definição de IRving S. OLDS, parecendo endossá-la: relações públicas "significa tôda criação ou emprêgo bem orientado de meios capazes de trazer para um empreendimento o conceito favorável da opinião pública". (27)

Walter Poyares define relações públicas como o "método de incorporar às correntes de opinião pública juizos relativos a uma pessoa, organismo ou instituição, de modo a provocar atitudes de aceitação, aplauso ou cooperação". (28) 
As três definições acima citadas fogem à bilateralidade indicada por BERNAYS, característica essa que o fizera considerar a integração e campo de atividade mais importante, aquêle que obriga o consultor a procurar ajustar as diretrizes e ações de seu cliente à sociedade.

A definição oficial da A.B.R.P., indicada por Hugo BARBIERI, parece-me bem mais aceitável, embora a do Instituto Britânico, em que ela se baseia, seja mais simples e sugestiva: "Entende-se por relações públicas o esfôrço deliberado, planificado, coeso e contínuo da alta administração para estabelecer e manter uma compreensão mútua entre uma organização pública ou privada e todos os grupos e pessoas a que esteja direta ou indiretamente ligada". (7)

Tendo sempre presente a idéia de bilateralidade, tanto como meio quanto como fim, preferi equilibrar em uma definição os campos de atividade, o objeto e os objetivos de relações públicas.

Considerando a identidade da conceituação de relações públicas governamentais e de emprêsas privadas, tenho usado neste artigo exemplos tomados de um ou de outro setor. A definição que proponho aplica-se, por conseguinte, indistintamente, a ambos os casos. E' a seguinte:

"Relações públicas é a função administrativa por meio da qual uma instituição, ora informando e guiando a opinião pública, ora pesquisando-a e deixando-se por ela guiar, busca identificar o seu interêsse privado com o interêsse público, desincumbindo-se de suas obrigações para com a sociedade e conseguindo e mantendo a compreensão, a aquiescência e o apoio desta".

Esta é a definição de um teórico, de alguém que, como CHILDS, procura ver as relações públicas como elas devem ser, e não como elas, infelizmente, ainda estão sendo. E talvez seja a confiança que tenho na vitória final do que é certo e do que é justo a razão pela qual coloquei a minha pena a serviço do progresso das relações públicas em nosso país.

\section{OBRAS CITADAS}

(1) Chaves, Sylla M'. -- "Fo:mação de Profissional de Relações Públicas" in Revista do Serviço Público, Vol. 91, ns. 1, 2 e 3. Ria de Janeiro, abril-junho de 1961, p. 53-81.

(2) Associação Brasileira de Relações Públicas - "Ciclo de Palestras Realizadas de 16-I a 15-II-1962" - Anexo ao Boletim da Seção Guanabara, a ser distribuido em maio de 1962.

(3) Jameson, Samuel H. - "Funções das Relações Públicas" (Textos Selecionados de Admiristração Pública - 4e volume). Rio de Janeiro, 1962 (no prelo). Universidade da Califórnia do Sul - projeto brasi- 
leiro, em cooperação com a Escola Brasileira de Administração Pública. Segunda edição, revista por S.H.J. e Sylla M. Chaves.

(4) Cuturp, Scott e Center, Allen - "Effective Public Relations New York, Prentice-Hall, 1952, p. 49 e 63.

(5)Bernays, Edward L. - "Public Relations" - University of Oklahoma Press, Oklahoma, 1952, p. 123.

(6) Childs, Harwood e outros - "Summary of Lectures and Discussions of the Short Course in Public Relations" pelo American Council on Public Relations, 1939. Stanford Univjersity, p. 19, Washington University, p. 42.

(7) BARBIERI, Hugo - "O que vem a ser relações públicas" in Relações Públicas na Indústria - Centro e Federação das Irdústrias do Estado de São Paulo, 1960 - p. 13.

(8) CANFIEld, Bertrand - "Relaçốos Públicas" - tradução de Olivia Klähenbühl - Livraria Pioneira Editôra, São Paulo, 1961, p. 5.

(9) FourlleE, Alfredo - "Historia Genaral de la Filosofia" - Zig-Zag. Santiago do Chile, 1943 - $3^{\circ}$ vol. p. 38-42.

(10) Chrnds, Harwood L. - "An Introduction to Public Opinion". New York, John Wiley \& Sons, 1949, p. v., 3, 25, 33 e 48.

(11) Carlson, Eric - "Curso de Relações Públicas", série de apostilhas, Escola Brasileira de Administração Pública, Rio de Janeiro, 1953.

(12) Chirds, Harwood L. - "Curso de Relações Públicas", série de apos. tilhas, Escola Brasileira de Administração Pública, Rio de Janeiro, 1953.

(13) Tсhakhotine, Serge - "Le Viel des Foules par la Propagande Politique". Paris, Gallimard, 1952.

(14) PACKard, Vance - "A Nova Técnica de Convencer (Hiddrkn Persuasers), tradução de Aydano Arruda. São Paulo, IBRASA, 1959.

(15) Harlow, Rex F. - "Social Science in Public Relations". Harper E Broters, New. York, 1957, p. 85.

(16) Sehwerert Ferrer, Arnaldo - "Relaciones Publicas", Ministério de Obras Públicas, La Habana, 1959, p. 38-39.

(17) Baus, Herbert M. - "Relações Públicas - Dinâmica e Prática", tradução de Carlos Peixoto de Castro. Rio de Janeiro, 1961. Editôrá Fundo de Cultura, p. 174.

(18) Silva, Benedicto - "Relações Públicas, Divulgação e Propaganda". Rio de Janeiro, 1954. Caderno de Administração Pública ri 1 . Escola Brasileira de Administração Pública.

(19) SAuvy, Alfred - "A informação, chave da democracia", tradução in Revista do Serviço Público. Rio de Janeiro 71(2), maio 1956 p. 224 .

(20) Bernays, Edward L. - "Propaganda" - 5" edição, 1936. New York, Liveright Publishing Corporation - p. 37.

(21) Rostand, Jean - "La Vulgarisation Scientifique: Entneprise de Dépaupérisation Intellectuelle", in Informations Unesco, n* $355-22$-IV1960 , p. 17-19.

(22) PASCAL, Blaise - "Pensées sur la Religion et sur Quelques Autres Sujets", Paris, Librairie Garnier Frères, 1913. - p. 247. 
(23) Gide, André - "Les Nourritures Terrestres, 75e. éd., p. 18.

(24) Pimlott, J. A. R. - "Public Relations and American Democracy" Princeton, New Jersey, Princeton University Press, 1951 - p. 205 e 214 .

(25) Chaves, Tullio - "Um Varão de Plutarco", prefácio a Ensaios e Criticas, obra póstuma de Alfredo Varela. Rio de Janei-o, Edições Instituto América, 1948 - p. 56.

(26) OBermeyer, Henry - "Is Advertising Losing Out?" in Printer's Ink, 6 fev. 1948, p. 136.

(27) Simas Pereira, Evaldo - "Relações Públicas e Vendas", texto impresso de uma palestra pronunciada no dia 17 de abril de 1958 no Auditório da A.B.I. - p. 8.

(28) Poyares, Walter - "Conceito di Relações Públicas", anexo ao Boletim n 134 da A.B.R.P., seção Estado da Guanabara, p. 6. Artigo extraido do "Observador Econômico e Financeiro" de novembro de 1958. 